\title{
Gestão do desempenho humano: um estudo de caso em um Hospital Geral de Fortaleza (CE)
}

\author{
Administration of the human acting: a case study \\ in a General H ospital of Fortaleza, Ceará State
}

$M$ aria de Fátima $M$ arrocos Fontenele ${ }^{1}$

Abstract Thethematic of this work presents questions on the practice of the Evaluation of functional performance in an organization of public health. Thisaxle of analysisgainsimportancefrom the difficulties of developing evaluation systems with alliances between policies of concession of financial incentives, in a specific cultural context. In this di rection, it is necessary to admit the limits of this management tool. From a qualitative re search, a semi-structured questionnaire was applied to the staff ( public servers) of a public general hospital of Ceará State. It was observed the characterization of the performance evaluation system used in the institution, being able to verify its adequacy to the models proposed in the literature and the relevancy of its intentions with the perceptions and expectations of the searched servers. Key words Performance management in health, Performance evaluation system, Incentives
Resumo A temática destetrabalho apresenta questões sobre a prática da avaliação de desempenho funcional em uma organização pública de saúde. Este eixo de análise ganha destaque a partir das dificuldades de desenvolvimento de sistemas de avaliação com alianças entre políticas de concessão de incentivos financeiros, em um contexto cultural peculiar. N esse sentido, é necessário admitir os limites dessa ferramenta gerencial. A partir de uma pesquisa qualitativa, utilizou-se um roteiro semiestruturado de perguntas aplicado aos servidores de um hospital geral público do Estado do Ceará. O bteve-se a caracterização do sistema de avaliação de desempenho utilizado pela instituição, podendo-se verificar sua adequação aos modelos propostos na literatura e a pertinência de seus propósitos com as percepções e expectativas dos servidores pesquisados.

Palavras-chave Gestão do desempenho em saúde, Sistemas de avaliação de desempenho, Incentivos
${ }^{1}$ H ospital Geral de Fortaleza, Secretaria da Saúde do Estado do Ceará. RuaÁvila Goulart 900, Papicu. 60155-290 Fortaleza CE. fatimamarrocos @hgf.ce.gov.br 
Introdução

Uma organização pública de saúde envolveintricadas relações entre seus diversos atores: usuários, profissionais, gestores, provedores, dirigentes, políticos esegmentos empresariais. A despeito das particularidades inerentes ao ritmo dos acontecimentos em organizações públicas ser diferenciado do competitivo mundo corporativo, as inevitáveis mudanças provocadas pela realidade política, econômica e social mundial trazem desafiantes paradigmas e tendências no que se refere ao gerenciamento do desempenho de pessoas, ao desenvolvimento de habilidades e competências ${ }^{1}$.

As avaliações de desempenho são instrumentos de tomada de decisões e de definição de políticas de gestão de pessoas. 0 processo de avaliação é tão importante quanto as conclusões geradas por ele, pois permite a compreensão de necessidades. As avaliações são instrumentos de mudanças desdeque possuam a credi bilidadedas pessoas envolvidas.

Por meio de abordagem qualitativa, este estudo colheu percepções e expectativas de servidores de diversas categorias profissionais sobre o sistema de avaliação adotado pelo hospital que serviu como campo empírico, as quais foram analisadas à luz de referencial teórico.

Por percepções, foram considerados os significados e definições atribuídos pel os servidores sobre o referido sistema, tal como este efetivamente se processa. Por expectativas, as falas dos servidores que apontavam para um modelo idealizado de avaliação, isto é, os julgamentos sobre como o sistema deveria se efetivar.

A definição da amostra foi por meio de crité riosqual itativos, no decorrer do trabalho de campo. Quando as respostas colhidas se repetiram, num processo de saturação, delimitando a suficiência de dados, os sujeitos pararam de ser abordados².

As bases da análise dos dados colhidos foram três categorias conceituais ou áreas temáticas que caracterizaram o sistema de avaliação: estrutura, processo eresultados. Essas categoriasforam identificadas por meio das percepções e expectativas dos sujeitos empíricos da pesquisa.

\section{Enfoques teóricos epráticos}

Alguns postulados de gestão que caracterizam a organização orientada para responder com efetividade ao ambiente globalizado foram preco- nizados por Lawler III ${ }^{3}$ t toda a força de trabalho deve participar do negócio; todos os funcionários devem agregar valor às atividades realizadas pela organização em que trabalham; é preciso promover a horizontalização dos processos e a liderança deve ser compartilhada em todos os níveis da empresa.

Embora essa seja uma realidade condizente com o competitivo mundo corporativo, não poderia ser diferente com o setor público, pois os que nele atuam também são atingidos por um turbilhão de exigências dos contextos culturais, trabalhistas, éticos e organizacionais. N o entanto, entreo quedeveria ser e o que, de fato, ocorre no hospital geral, há uma grande diferença.

A gestão de pessoas nos serviços de saúde ganha conotações peculiares em função do significado que tem o trabalho no processo de produção dos serviços, incluindo os interesses implícitos. Segundo Campose Santana4, "[...] o trabalho em saúde tem implicações especiais porque não se trata apenas de uma mercadoria cujo valor seestipule de acordo com as regras de mercado. É um processo onde se realizam múltiplos e variados interesses."

Existeuma teia de efeitos produzidos pela interação entre trabal hadores da saúde, dirigentes, clientes eos sentimentosqueessas interações suscitam na dinâmica do processo de trabal ho no hospital geral de Fortaleza. Dentre esses efeitos, estão aquel es ligados especificamente à multiplicidade de relações de emprego e de trabal ho no SistemaÚ nico de Saúde(SUS), quetêm implicações profundas no desenvolvimento de sistemas de avaliação de desempenho funcional eno reconhecimento do mérito.

\section{A abordagem estrutural do programa de avaliação}

A abordagem estrutural do programa de avaliação abrangeu o conhecimento eo significado atribuído pelos sujeitos pesquisados aos pressupostos do programa, à sistemática e dinâmica das avaliações, aos objetivos propostos, aos critérios para concessão de incentivo financeiro, denominado Gratificação de Incentivo ao Trabalho com Qualidade (GITQ), resultante das avaliações do referido programa. Este, em suas bases, revela a pretensão de estimular a participação e o compromisso de equipes com os objetivos organizacionais, estabelecendo-se melhoria no fluxo de informações entre empregados e gestores. Isso coaduna com que Quimper e Lecrec, citados por 
Dal Poz, Pierantoni eVarela ${ }^{5}$, comentam sobrea gestão do rendimento no futuro: " terá que levar em conta diferentes elementos, como a capacidade de 'escuta', o interesse em relação à percepção e idéias dos empregados".

Ocorre uma ênfase na escuta dos usuários dos serviços de saúde, sendo inegável sua importância como mecanismo de controle social. No entanto, há pelo menos dois lados nesse processo, com suas respectivas versões: quem recebe 0 atendimento e quem presta o serviço. 0 desempenho funcional e os compromissos assumidos pelas instituições também devem ser avaliados.

Em face das expectativas dos servidores voltadas fortemente para a promoção funcional como resultado das avaliações de desempenho, permite-sefazer as mesmas ponderações de Böhmerwald ${ }^{6}$, quando diz que, por muito tempo, a avaliação de desempenho esteve somente atrelada à promoção por mérito, causando certa frustração e reações contrárias quando isso não acontece. A falta de hábito, por parte das organizações do setor público, em estabelecer metas eavaliar a produtividade, traz dificuldades aos funcionários para distinguirem outros objetivos do processo e 0 impedimento de ações corretivas sobre os desvios de desempenho.

Nos depoimentos dos servidores, um desconhecimento generalizado dos propósitos, crité rios e das intenções do programa de avaliação foi evidenciado: Os critérios não são claros, então isso para mim não existe. Eu às vezes sei que sou avaliado, mas acho quenão existe um critério pelo menos conhecido; não conheço, não sei. (Servidor cirurgião-dentista)

Uma das características fundamentais atribuída por Bergamini e Beraldo 7 à avaliação de desempenho em termos institucionaiséa de oportunizar o entendimento entre as pessoas, favorecendo o diálogo entre chefias e colaboradores, 0 autodesenvolvimento diante da revisão e a atualização permanente do seu próprio comportamento.

Conquanto relacionamento, aperfeiçoamento e inovação no trabalho sejam fatores constantes nos instrumentos de aval iação do programa, sua utilização prática está longe de oportunizar o que deveria. Situa-se nas expectativas: 0 certo seria fazer uma avaliação de desempenho do funcionário e do desempenho da chefia, em nível de relacionamento, de melhoras desse relacionamento, de iniciativa, como é que a pessoa tá desempenhando sua função, seu cargo e crescimento. (Servidor psicólogo)

Tal depoimento reforça que a gestão de recursos humanos surge com o propósito da utiliza- ção plena das competências individuais por meio da integração da cultura, filosofia, políticas e práticas desenhadas para garantir o compromisso e o desenvolvimento profissional. No entanto, como pondera Drucker ${ }^{8}$, "Talvez tenhamos de redefinir totalmente a tarefa. E ela pode não ser 'administrar o trabalho das pessoas'. 0 ponto de partida, tanto na teoria como na prática, talvez tenha de ser 'administrar para o desempenho'".

0 desconhecimento do programa de avaliação faz com que seja reduzido a uma rotina de preenchimento de fichas e questionários, burocracia técnica distanciada de suas realidades, sem clareza do significado, nem tampouco de resultado prático; em suma, um controle imposto por uma instância maior da organização: 0 que eu percebo é assim, que essas avaliações vêm como tendo que ser feitas, um prazo pra fazer, sem maiores esclarecimentos. Tem que ser feito nas carreiras, de qualquer jeito e acabou. (Servidor assistentesocial)

Os depoimentos denotaram que as funções básicas da avaliação de desempenho descritas por Levinson ${ }^{9}$ são despercebidas: o fornecimento de feedback sobre o desempenho de todas as pessoas; a utilização dos resultados como base para mudanças de comportamento em direção a atitudes mais eficazes e a utilização desses dados pelos gerentes para distribuir atribuições e remunerações.

Conquanto essa dificuldade possa ser atribuída à falta de informação, consequência do pouco alcance da divulgação interna sobre os objetivos do programa, deve-se considerar que isto se soma à inadequada utilização de resultados obtidos, que poderiam contribuir para a melhoria na execução dos trabalhos.

\section{A abordagem de processo do programa de avaliação}

0 fundamento da abordagem de processo é a própria condução e desenvolvimento do modelo na prática. É como ocorrem as avaliações do programa de avaliação na percepção dos servidores. 0 efeito das avaliações em si próprios, em suas interações com os outros membros da equipe de trabalho e com suas chefias.

Tão curiosa quanto antiga, a expressão "para inglês ver" revela, segundo Caldas e Wood Jr. ${ }^{10}$, a intenção de criar uma realidadeilusória para provocar algum efeito perante al guém que se respeita ou teme, sem, no entanto, mudar substancialmente o que vai além da aparência. É um "fazer 
de conta" que envolve manipulação da impressão e dissimulação.

É possível fazer uma correlação entre o que representa essa expressão e a realidade hospitalar em que se insere o programa de avaliação, quando surgem depoimentos indicando que as avaliações funcionais acontecem para se fazer cumprir o que é designado por meio dos instrumentos legais, como a lei e o decreto governamental que instituem a GITQ e as avaliações de desempenho para a sua concessão.

Como as avaliações não são confidenciais, os gestores têm livre acesso aos instrumentos, podendo identificar as avaliações de cada membro de sua equipe. Isto deixa os servidores pouco à vontade: Eu acho que as avaliações são feitas "pro forma". Porque como os chefes precisam identificar os funcionários, os funcionários precisam identificar o chefe; então, nenhum subordinado vai se contrapor à chefia. 0 chefe pelo seu poder de mando poderealmentevir prejudicar um servidor numa avaliação ou atémesmo depois dessa avaliação feita. (Servidor enfermeiro)

A retaliação por parte da chefia é evitada por meio do mascaramento da opinião dos servidores, quer superavaliando ou atribuindo às chefias um desempenho mediano: Eu procuro colocar as melhores notas possíveis, por que eu dependo da avaliação dela. Aliás, ela primeiro nos avalia, depois a gente avalia, mas o retorno ninguém vê. Eu procuro colocar na minha chefe as mel hores notas. (Servidor auxiliar de enfermagem)

Evidenciam-sea tendência central eo efeito de H alo em que se apóiam os servidores para avaliarem. Esses aspectos são tidos como um dos problemas potenciais da avaliação de desempenho. No erro de tendência central, os servidores optam por avaliações medianas de seus superiores; no efeito de $\mathrm{H}$ alo, terão propensão a atribuir notas altas, mesmo quenem todas as características estejam acima da média, por temerem retaliações e problemas. Para Bergamini eBeraldo ${ }^{7}$, as avaliações com esses erros não terão utilidade prática.

A realidade superficialmente correta é também objeto da reflexão de Benevides ${ }^{11}$ quando comenta que, na cultura brasileira, existeum forte traço de um formalismo legalista que, verdadeiramente, não passa de um "faz-de-conta", de "coisa para inglês ver", por que entre o queédeterminado e o que real menteacontece, ou seja, entreo formal e o real, existe muita diferença.

As expectativas dos servidores estão muito distantes do que percebem que é feito. Vislumbram que, em tese, o processo oferece oportunidades de reflexão, de participação ativa, de suge rir melhorias. Na prática, o programa de avalia- ção se dissocia desses objetivos e parece não funcionar, gerando descrença: Porque, na verdade, as pessoas fazem só para preencher o papel sem ter a noção da importância; das modificações que podem ser feitas, das conquistas que a gente podeter. Então, uma coisa que é respondida, sem se ter a noção do que está respondendo, eu acho que isso não étão significativo, a não ser que houvesse toda uma reformulação. (Servidor psicólogo)

Segundo Barbosa ${ }^{12}$, a problemática de planos de avaliação de desempenho e de reconhecimento do mérito somente será resolvida por meio da legitimidade prática e não por decretos ou outros mecanismos jurídicos e formais. A legalidade de um sistema de avaliação não implica sua legitimidade por parte dos atores envolvidos. Essa legitimidade só se estabelece quando há envolvimento das pessoas, quando compreendem o sentido e visualizam o impacto dos resultados, quando percebem a chance de aprender, crescer e melhorar no que fazem. 0 resultado da avaliação, longe de espelhar o desempenho real do servidor, espelha o caráter personalístico da relação chefes-subordinados: Eu sei que dentro do serviço público as coisas são políticas, se eu der a nota que eu acho, me prejudica no final; eu tenho que passar a mão na consciência e dar a nota que esperam que eu dê. (Servidor dentista)

Essa realidade constatada parece abstrair a importância do desempenho, principal critério para que se migre em direção a um paradigma de Estado prestador de serviços de qualidade.

A tradição da cultura administrativa brasileira, segundo Barbosa ${ }^{12}$, é profundamente autoritária, na qual todo novo plano de avaliação dedesempenho éintroduzido como uma maneira de punir, de "separar o joio do trigo". A avaliação nunca foi usada no Brasil como instrumento decrescimento e melhoria do serviço esim como um instrumento de punição de um corpo desmotivado de servidores, nunca beneficiado por uma política de capacitação sistemática ${ }^{12}$.

As marcas do período de ditadura militar, em que o traço de autoritarismo da cultura brasileira se revelou, sobremaneira, em forma de punição, também dificultam que a avaliação se constitua instrumento de aperfeiçoamento: A questão équea própria cultura da avaliação éuma cultura distorcida, até por conta de todo um período quea gente teve de autoritarismo, de ditadura militar, dequando sefalava em avaliação, sefalava em degola; essa cultura, essa ideologia ainda permeia muito o serviço público. (Servidor médico)

Portanto, há de se olhar criticamente a experiência histórica brasileira para quese aprofunde o debate sobre as nossas lógicas culturais e se 
rompa o círculo vicioso estabelecido entre proje tos novos e velhos não implementados ${ }^{12}$.

A ênfase no engajamento das pessoas para a melhoria contínua dos processos permeia as expectativas dos sujeitos pesquisados quanto ao programa de avaliação: U m sistema que seja democrático. Que realmente seja usado com seus objetivos. Queatinja os seus fins. Que seja de uma forma que realmente o servidor se sinta prestigiado e que seja essa uma forma de estimular a vestir a camisa da unidade e que ele se sinta inserido num processo de transparência. (Servidor assistente social)

No entanto, subjacente a esse engajamento e participação, está a comunicação queviabiliza os processos internos de mudança e melhoria. $\mathrm{Ne}$ nhum sistema de avaliação de desempenho será eficaz, seja qual for o seu propósito, a não ser que as pessoas que estão sendo avaliadas saibam - que se espera delas e conheçam os critérios pelos quais estão sendo julgadas. Esse é um dos pontos no qual há convergência entre os relatos e a literatura que tem sido produzida, quando a temática é avaliação de desempenho. 0 hospital geral parece encontrar problemas, carecendo de eficiência no planejamento, execução e gestão da comunicação: Acho que esse programa deve ser mais discutido; por isso que eu te digo que deve haver uma capacitação sistemática, um diálogo e quehá necessidade de uma forma mais dinâmica e mais objetiva. (Servidor enfermeiro)

Deacordo com Barbosa ${ }^{12}$, referenciando teóricos da qualidade, como Juran e Ishikawa, que afirmam que se 80 a $85 \%$ dos problemas das empresas são de origem sistêmica e não da responsabilidade individual dos funcionários, então, como avaliá-los devidamente? Como discernir, em um mau desempenho, a parcela de responsabilidade do sistema e a do indivíduo?

$\mathrm{Nem}$ sempre parece existir o discernimento entrea dimensão estrutural, sistêmica eindividual no processo de avaliação de desempenho no contexto hospitalar. 0 relato que segueindica essa falha do programa de avaliação: $\mathrm{Na}$ emergência do hospital, são cento e vinte médicos, mais auxiliares. Então, não existe, nem pode existir, um negócio desse, da chefia chamar um por um ejunto avaliar o funcionário. Só um chefe não tem condições de avaliar funcionário por funcionário sem conversar com ele; sem conversar não existe avaliação. Esse negócio de vocêfazer um xis no bom, no ruim, eu não acredito; não gosto desse tipo de avaliação. $N$ ão funciona. (Servidor auxiliar de enfermagem)

0 ataque mais famoso contra a avaliação de desempenho dos assalariados, segundo Barbo- $\mathrm{sa}^{12}$, partiu de Edward Deming. Para ele, o sistema anual de avaliação de desempenho énegativo por que é um sistema arbitrário e injusto, que desmoraliza os empregados, alimenta o desempenho imediatista, nulifica o trabalho em equipe, estimula o medo e a mobilidade administrativa.

No entanto, os próprios servidores sugerem alternativas para compensar as lacunas deixadas pelas dificuldades operacionais. Entre as sugestões, estão avaliações dos parceiros e equipes de trabalho, entrevistas e a autoavaliação, nos moldes do Feedback 360 Graus, tendência contemporânea de avaliação, um olhar plural que privilegia o diálogo entre as pessoas envolvidas, centradas no feedback, diferenciada dos métodos quantitativos tradicionais de avaliação: 0 grupo avalia o chefe, o chefe avalia o grupo e nós avaliaríamos a direção do hospital. Eu acho que deveria ser assim. (Servidor auxiliar de enfermagem)

Segundo Souza ${ }^{13}$, a avaliação é uma tarefa diária, independente de haver ou não um processo formalizado. As pessoas percebem que estão sendo avaliadas por suas chefias, companheiros de trabalho e por elas próprias, por ser uma consequência inevitável ao funcionamento de uma organização. Há expectativa dos servidores de que seja procedida uma avaliação mais informal e participativa, baseada no entendimento mútuo e com foco solidariedade: Temos que ser avaliados um pelo outro; sebem que essa avaliação é feita no dia a dia, no setor. No dia a dia, a gente avalia um ao outro por que a gente vê quem são aquel es quetêm qualificação, quem são aqueles que realmente são solidários com o outro. (Servidor auxiliar de enfermagem)

As expectativas de muitos servidores deparam-se com o que denota a falta de comprometimento dos próprios patrocinadores do processo de melhoria, que são as gerências, o que repercute negativamente: $A$ chefia prefere que as coisas sejam feitas, acabadas, independentemente da qualidade. $\mathrm{E}$ isso a gente bate de frente por que eu briguei muito por causa disso; para implantar qualidade no setor e nunca consegui. (Servidor farmacêutico-bioquimico)

Os gerentes no hospital geral não se constituem líderes visionários que proporcionam novas perspectivas para seus seguidores e para a organização, com descreve Kotter ${ }^{14:}$ : "Líderes são pessoas que escolhem a direção na qual a empresa ou organização deve caminhar, criam visões e estratégias, conseguem fazer com que as pessoas estejam dispostas a segui-los". 
A abordagem de resultados do programa de avaliação

Os sistemas de classificação e remuneração, caracterizados por utilizarem tabelas unificadas de remuneração, com melhorias automáticas, periódicas, baseadas em antiguidade e fixadas gene ricamente, para toda a administração, ainda constituem fator essencial para a motivação do de sempenho dos funcionários públicos. São sistemas embasados em abordagens tradicionais, com padrões determinados por uma autoridade central, que deixam pouca ou nenhuma margem para a valorização das diferenças individuais e para a flexibilidade ${ }^{15}$.

Um dos maiores problemas desses sistemas é a dificuldade imposta aos servidores de extrapolarem suas atribuições e desenvolverem novas qualificações, trazendo desestímulo à criatividade e ao espírito de iniciativa, uma vez que a remuneração só pode ser aumentada caso ocorra uma promoção à classe seguinte, ocorrendo o que denomina de "emperramento" 15 .

Os planos de cargos, carreiras e salários do setor público estadual obedecem a mesma lógica com regras fixas, como se pode observar: Que esses programas venham a influenciar a evolução da gente dentro do serviço público. Você entra no serviço público, passa um ano, dois anos, três anos. Você vê que o serviço, ele não pensava no seu crescimento; você cresce, seu currículo cresce e tudo, mas no serviço público você não sente, é muito lento; em onze anos, agora que eu consegui mudar uma vez de nível. (Servidor assistente social)

Apesar do investimento feito para o desenvolvimento profissional pelo próprio servidor, não há retorno na mesma proporção por parte da instituição, nem existe margem para inovação e criatividade na execução do trabal ho. N essa perspectiva, o programa de avaliação inspira nos sujeitos pesquisados o vislumbramento de oportunidades de investimento no desenvolvimento profissional e a melhoria na execução do trabal ho. As expectativas são as seguintes: Eu gostaria quetambém oferecesse, a empresa quea gente trabalha. Pra gente melhorar também o serviço. 0 aperfei çoamento da gente, investir mais no profissional, sabe? Com cursos, pra gente fazer reciclagem. Porque, por exemplo, a gentetermina a faculdade eaí fica aqui dentro, só bitolada, vendo aquiIo ali. Deveriam oferecer mais. (Servidor farmacêutico-bioquímico)

Segundo Costin ${ }^{16}$, a mudança do perfil de atuação do Estado abrange uma revisão de sua política de recursos humanos, incluindo sistema de avaliação de desempenho, capacitação e planos de carreira, entre medidas voltadas para 0 melhor aproveitamento dos servidores. No entanto, o grande viés da política sal arial do serviço público nos países sob reforma, como assinala Nunberg ${ }^{15}$, é a utilização da política de gratificações e subsídios como forma de compensar as deficiências dos sistemas de remuneração e de benefícios. 0 Estado, essencialmente paternalista, estabelece com seus servidores uma relação de piedade, sem Ihes exigir ou recompensar o desempenho compromissado com a qualidade dos serviços.

Frequentemente, vê-se nas organizações me didas sendo tomadas mediante critérios de premiação por produtividade, acreditando-se que, quanto mais recompensa o trabalhador receba, mais e melhor vai empenhar-se na realização do trabalho. Há uma complexidade muito maior que precisa ser levada em consideração, como as características e as experiências vivenciadas; a natureza do trabalho esuas restrições ea organização com suas regras, políticas e práticas de recursos humanos, contexto da interação entre todas essas variáveis ${ }^{15}$.

Os métodos tradicionais de avaliação de desempenho, resultando em recompensas financeiras, parecem transformar-se em uma polêmica discussão salarial: Ao invés de o governo se preocupar com o salário do servidor, incentivá-lo de outras formas, através de capacitação, através de oportunizar condições de trabalho, ele fica dando benefícios indiretos e, às vezes, em vez de incentivar, faz o efeito contrário. Onde há incentivo se não há condições de trabalho? Se não há um incentivo à capacitação? U m plano de capacitação anual, uma proposta?Essa capacitação émuito mais pontual do que, na verdade, uma programação sistemática para a qualidade do trabalho. (Servidor fisioterapeuta)

O depoimento parece confirmar as críticas de Kohn ${ }^{17}$ sobre incentivos e recompensas, quando advoga que, frequentemente, corroem o próprio processo que pretendem incrementar. A esse fracasso atribui-se uma inadequação dos pressupostos psicológicos que fundamentam esses tipos de planos. As recompensas, como as punições, asseguram somente uma submissão temporária, pois são ineficazes quando se trata de produzir mudanças duradouras de atitude e comportamento.

Os incentivos não alteram as atitudes que estão subjacentes aos comportamentos humanos; não criam compromisso duradouro. A questão da GITQ, na percepção dos servidores, parece corroborar com a perspectiva teórica de Kohn ${ }^{17}$ : 
Eu não vou dizer que a minha produtividade aumentou, que melhorou a minha qualidade de serviço. Eu não faço a relação da produtividadecom a melhora do serviço; agora, a questão da avaliação, você sempre tem um empenho maior quando você se sente sati sfeito. (Servidor fisioterapeuta)

Diferentemente, oferecer oportunidades de desenvolvimento profissional, por meio de cursos e treinamentos, parece favorecer a valorização dos servidores, tornando-se mecanismos aceitos, com maior impacto no desempenho ena produtividade. Surgem expectativas ereivindicações nesse sentido: Há falta de incentivo, há cobranças de muito trabalho e pouco incentivo. Eu sempre conversei com a minha chefia sobre isso nesses doze anos: "procura ver cursos para a gente, procura capacitar a gente não só naquilo que nós estamos fazendo, mas em outros cursos". (Servidor auxiliar de enfermagem)

Grande parte das abordagens sobre motivação destaca os conceitos de necessidade e de expectativa. Preconiza quenão ésuficienteconsiderar apenas as necessidades como determinantes do comportamento do trabal hador; deve-se considerar também em que grau esse trabalhador percebe as condições existentes no ambiente da organização, como facilitadoras, ou não, de seus próprios objetivos. Robbin $s^{18}$, numa síntese que representa essa lógica, afirma que "a motivação é o resultado da interação entre o indivíduo e a situação".

Inúmeras foram as teorias cognitivas criadas sobre as necessidades humanas esobre como elas determinam o comportamento no contexto das organizações, para com isso serem estabelecidos programas de incentivos ao desempenho no trabalho. A busca de mecanismos que estimulem a satisfação dos empregados tem sido perseguida como se fosse a própria motivação para executá-lo. Segundo Bergamini e Beraldo7, "a ênfase dada às medidas de compensação pelo bom desempenho foi tão acentuada que a satisfação passível de ser conseguida pelo trabalho acabou sendo confundida com a própria motivação para executá-lo".

A concessão de incentivos extrínsecos pode ser um fator de recompensa pelo trabalho realizado, a troca objetiva do trabal ho pela remuneração: Eu acho que é um incentivo bom, por que pra tudo na vida você tem que ter um incentivo, você tem que ter um estímulo. Está certo que é o seu trabalho, mas você trabalha pra isso. (Servidor cirurgião-dentista)

No entanto, o reconhecimento, também percebido como algo mais amplo que envolve a de- dicação, o comprometimento, pode transcender as recompensas financeiras: Dinheiro pode estimular e pode não estimular. É um fator de reconhecimento, digamos, pelo seu trabalho. (Servidor assistente social)

De qualquer forma, planos de incentivos aliados a outras políticas de gestão de pessoas podem ser eficazes. Ou, como diz Ulrich ${ }^{19}$, "o dinheiro pode ser um bom fator de motivação se vier em quantidade significativa e se seu ganho estiver associado a objetivos específicos".

Segundo Nunberg ${ }^{15}$, não obstante a filosofia sobre a avaliação de desempenho tenha mudado, na prática, muitas vezes ela é uma fonte de atritos, insatisfações e frustrações não somente para aqueles que a concebem e aplicam, como para aqueles que são alvos de sua aplicação.

As percepções dos sujeitos sobre as reações do próprio grupo de trabalho, diante das avaliações, parecem confirmar características do programa de avaliação, tais como, foco do controle hierárquico top-down, a prática classificatória ea ausência de negociação de resultados, identificando novamente o sistema utilizado com as posturas dos métodos mecanicistas tradicionais: N ós até ficamos um pouco apreensivos, preocupados. Nós não sabíamos a que, como era que ia chegar a prejudicar ou não a nossa função. (Servidor agente administrativo)

Objeto de estudo para Prates e Barros ${ }^{20}$, em uma situação de desigual dade de poder, a relação entre indivíduos pode levar a um grau de alienação, baixa motivação, consequentemente, pouca iniciativa. Percebendo-se alvos de medidas punitivas, resultantes de avaliações, os servidores reivindicam o mesmo tratamento para as chefias que não obtiveram bons conceitos: 0 funcionário étrocado de setor, o funcionário éremanejado. $M$ as 0 chefe não, ele permanece intacto, ninguém toca no chefe. (Servidor atendente de enfermagem)

É possível observar a percepção dedesigualdade na relação desempenho e recompensa. Parece não existir entre os servidores o sentimento de reconhecimento do desempenho nas atividades por meio da GITQ a ponto de ser decretada a própria inutilidade desta gratificação: A minha opinião sobrea GITQ querecebo, ela éa maisinjusta possível, porque ela, a GITQ , não avalia o meu trabalho. (Servidor atendente de enfermagem)

Além dos sentimentos de satisfação ou insatisfação entre os funcionários, decorrentes das comparações entre esforço e o desempenho na realização do trabalho, a competência profissional e as habilidades com as recompensas recebidas, inevitavelmente, para Beer e Walton ${ }^{21}$, sur- 
gem, também, comparações entre os funcionários que ocupam posições semelhantes dentro da organização. N o processo natural de comparações, está a busca por um tratamento justo que encontra explicações na teoria da equidade, de Adams, como se observa: A GITQ devia ser pela iniciativa do funcionário, pela assiduidade do funcionário. Eu posso muito bem passar o dia sem trabalhar, passar o dia todinho numa boa e não fazer nada e estou ganhando como colegas meus estão, não fazem nada e ganham do tanto que eu ganho, injusto! (Servidor auxiliar deenfermagem)

Considerando a teoria da equidade, comentada por Robbins ${ }^{18}$, os indivíduos não somente se preocupam com a quantidade absoluta de recompensas que recebem pelo seu desempenho, mas com a relação desta quantidade com que os outros recebem. N essa comparação, tem-se a percepção do desequilíbrio entre seus esforçose desempenho no trabalho em relação a outros, movendo as pessoas a lutarem pelo que percebem como equidade ejustiça.

Contrária a planos de incentivos como estratégia de gerenciamento, Sanford ${ }^{22}$, tal como Kohn ${ }^{17}$, aponta graves falhas na base teórica do que denomina "cultura dos incentivos". É necessário que as pessoas sejam muito subservientese se concentrem em certos comportamentos prescritos ou, ainda, que se preocupem apenas com os benefícios pessoais diretos que poderão alcançar com seus esforços, entrando em competição com seus próprios colegas de trabalho ${ }^{22}$.

Sanford ${ }^{22}$ crê que as organizações que possuem a cultura dos incentivos homogeneízam os meios deresolver seus problemas, acabando com o desenvolvimento e a expressão das singularidades dos indivíduos.

A distribuição da GITQ é diferenciada entre categorias profissionais, estabel ecendo hierarquia dentro de grupos já formados, adotando critérios discriminatórios para servidores médicos, denominados de nucleares, servidores de nível superior não nucleares e servidores com escolaridade do nível secundário. Essa triangulação na lógica distributiva da GITQ parece provocar resistência entre os servidores, deslegitimar o mé rito do desempenho e o valor do trabalho em equipe e das relações pessoais: $\mathrm{E} 0$ que a gente nota em relação ao desempenho dos profissionais da área paramédica é intenso e há uma discriminação em relação ao médico que sempre é priorizado. Eu acredito que dentro de um hospital todos têm uma função importante e interligada. (Servidor fonoaudiólogo)
Sobre essa diferenciação, $\mathrm{M}$ alik ${ }^{23}$ relata que grande parte do que se denomina organizações de saúde tem relação direta com seus recursos humanos, fazendo parte do que alguns teóricos caracterizam de "organizações profissionais", nas quais são valorizados as habilidades e conhecimentos imprescindíveis para as atividades fins.

É uma realidade propensa a conflitos, exigindo um processo permanente de negociação que, na verdade, caracteriza-se um grande desafio para a cooperação no trabalho entre os diferentes atores.

Tanto indivíduos como organizações possuem expectativas enecessidades específicas. A base dainteração e do relacionamento entreesses dois componentes, indivíduo eorganização, para atender às expectativas mútuas, secaracteriza em uma espécie de vínculo contratual implícito, o contrato psicológico, que, segundo Roosevelt Jr. ${ }^{24}$, tem implicações na produtividade e na satisfação das pessoas.

As expectativas evidenciadas pelos servidores pesquisados sobre o programa de avaliação relacionam-sea terem o desempenho avaliado ereconhecido, obterem melhores condições de trabaIho eoportunidades de desenvolvimento: Credibilidadedas pessoas. Eu espero isso; que las acreditem no que eu estou fazendo, no que eu desempenho. A poio e reconhecimento. (Servidor enfermeiro)

De acordo com Lucena ${ }^{1}$, a ação gerencial sobre o desempenho, por meio do acompanhamento, requer aproximação com seus colaboradores, para receber e dar feedback, provendo os meios de realização do trabalho, ajustando as prioridades, identificando e atendendo as necessidades e utilizando de forma eficaz as capacidades disponíveis.

No contexto do hospital geral, o retorno dos resultados das avaliações parece não ter relevância: A gentenão senteémelhoria devolta, decorreção. A gentenão vêação concreta. (Servidor assistente social)

0 quadro de feedback limitado, a falta de re torno aos servidores, pode se constituir em um dos mais graves erros e fragilidade do programa de avaliação. Fornecer feedback é a forma de envolver as pessoas no processo, tornando-o significativo elegítimo.

As lideranças efetivas devem conhecer seus colaboradores para darem respostas apropriadas às suas necessidades. Devem lembrar que seus seguidores desenvolvem, enquanto indivíduos, seus próprios padrões de conduta. 


\section{Conclusões}

A pesquisa revelou que a prática de avaliação de desempenho no hospital geral, no que tange ao acompanhamento, análise e feedback dos resultados, à disseminação de informações, à prática dediscussões, de julgamento ou dediálogo ainda requer avanços e mudanças predominantemente culturais.

$\mathrm{Na}$ perspectiva de estrutura do programa de avaliação, evidenciou-sedesconhecimento generalizado acerca da metodologia, critérios e objetivos estabelecidos para as avaliações, perdendo a visibilidade necessária.

$\mathrm{Na}$ perspectiva de processo, o programa de avaliação caracteriza-se pelo predomínio deuma prática que não estimula a participação, o comprometimento, o desenvolvimento profissional nem a pretendida melhoria dos resultados. Parece alinhar-se com posturas gerenciais tradicionais caracterizadas pela centralização do poder, o personalismo e a maneira relacional de subsidiar o reconhecimento, a valorização e a distribuição da GITQ . Ficou explicitado queas posturas tradicionais favoráveis ao julgamento valorativo nas avaliações, enraizadas na cultura organizacional, superam as posturas das lideranças favoráveis ao diálogo.

Há evidências aparentemente paradoxais: por um lado, os pesquisados consideram o programa deavaliação importantemecanismo deidentificação de pontos críticos e demelhorias internas, quer sejam relacionadas às condições de trabaIho, tidas como estruturais, como de desenvolvimento profissional e pessoal. Por outro lado, es- sas benfeitorias ficam no plano do ideal, das expectativas decomo deveria ser um sistema deavaliação, pois, na prática, os avanços não se evidenciam, não são percebidos como resultantes das atividades do programa de avaliação, nem tampouco parecem estar ao alcance deles, servidores.

$\mathrm{N}$ a perspectiva de resultados, os sujeitos pesquisados são unânimes em afirmar que não recebem retorno das avaliações, gerando descrença e nenhuma legitimidade ao programa de avaliação. Os resultados das avaliações deveriam subsidiar medidas administrativas e políticas internas de recursos humanos.

No ambiente do hospital geral, parece haver pouco estímulo ao empreendedorismo eà criatividade, resultantes, principal mente, da prática do modelo de gestão piramidal e da quase invencível burocracia.

A pesquisa aponta que a aliança entre avaliações e concessão de incentivos e gratificações financeiras, como rege o programa de avaliação, tem sido comprometida pel os critérios estratificadores das categorias profissionais, bem como da falta de imparcialidade das chefias nas decisões, inibindo a realização de avaliações mais coerentes e verdadeiras por parte dos servidores, diante de possíveis punições e retaliações.

Os servidores desejam oportunidades de participar de discussões e decisões, de analisar e decidir prioridades, além de políticas de desenvolvimento de recursos humanos. A busca da qualidade se dá pela valorização do ser humano e do processo que origina a construção conjunta de uma realidade melhor no Sistema Ú nico de Saúde estadual. 


\section{Referências}

1. Lucena MDS. Avaliação de desempenho. São Paulo: Atlas; 1992.

2. Benevides MG. Entre ovelha negra e meu guri: construção da identidade social do delinquente juveni pobre no processo de socialização na família [dissertação]. Fortaleza (CE): Universidade Federal do Ceará; 1996.

3. Lawler III E. Estratégia versus Funcionários. Rev HSM M anagement 1998; 10(2):12-15.

4. Campos FE, Santana JP. Política de recursos humanos em saúde. Brasília: M inistério da Saúde; 2002. p. 9-12.

5. Dal Poz MR, Pierantoni CR, Varella TC. Produtividade e Desempenho dos Recursos H umanos nos Serviços de Saúde. Brasília: OPAS; 1997.

6. Böhmerwald P. Gerenciando o sistema de avaliação de desempenho. Belo Horizonte: Editora de Desenvolvimento Gerencial; 1999.

7. Bergamini CW, Beraldo DGR. Avaliação de desempe nho humano nas organizações. 4ạ ed. São Paulo: Atlas; 1988.

8. Drucker PF. 0 melhor de Peter Drucker: a administração. São Paulo: Nobel; 2001.

9. Levinson $\mathrm{H}$. Avaliação de que desempenho? In: Vroom VH, organizador. Gestão de pessoas, não de pessoal. 9a ed. Rio de Janeiro: Campus; 1997. p. 189203.

10. Caldas MP, Wood Jr. T. Transformação e realidade organizacional: uma perspectiva brasileira. São PauIo: Atlas; 1999.

11. Benevides, M G. Administrando com jeitinho (?): o perfil do administrador público. [acessado 2003 nov 15]. Disponível em: https://ead2.unifor.br/cadinetv03/ Arquivos/p2510020/02 - administrando - com jeitinho

12. Barbosa L. M eritocracia à brasileira: o que é desempenho no Brasil? Revista do Serviço Público 1996 47(4):3-4.

13. Souza VL. Gestão de desempenho: julgamento ou diálogo? Rio de Janeiro: Editora FGV; 2002.

14. Kotter JP. Os líderes necessários. Rev H SM Management 1997; 4(1):6-12
15. Nunberg B. Gerência de recursos humanos no setor público: lições da reforma em países desenvolvidos. Cadernos EN AP 1993; 14.

16. Costin C. Por um Estado que funcione. Brasília: M inistério da Administração Federal e Reforma do Estado; 1997.

17. Kohn A. Por que os planos de incentivo não funcionam. RAE 1995; 35(6):12-19.

18. Robbins SP. Comportamento organizacional. $8^{a} \mathrm{ed}$. São Paulo: LTC; 1999.

19. Ulrich D. Liderança que leva a resultados. Rev HSM $M$ anagement 2004; 42(8):152-158.

20. Prates MAS, Barros BT. 0 estilo brasileiro de administrar. In: Motta FCP, Caldas MP, organizadores. Cultura organizacional e cultura brasileira. São Paulo: Atlas; 1997.

21. Beer M, Walton RE. Nota da Harvard Business School: Sistemas de recompensas e o papel da remuneração. In: Vroom VH. Gestão de pessoas, não de pessoal. 9 a ed. Rio de Janeiro: Campus; 1997. p.19-35.

22. Sanford C. Liderança pela motivação: a ética e a praticidade dos incentivos. In: Renesch J, organizador. Liderança para uma nova era. São Paulo: Cultrix-Amana-Key; 1994. p. 35-45.

23. Malik AM. Gestão de Recursos Humanos. Vol. 9. São Paulo: Faculdade de Saúde Pública da Universidade de São Paulo; 1998. Série Saúde \& Cidadania.

24. Roosevelt Jr. RT. Nota da Harvard Business School: Como gerenciar o contrato psicológico. In: Vroom VH. Gestão de pessoas, não de pessoal. 9a ed. Rio de Janeiro: Campus, 1997. p. 37-53.

Artigo apresentado em 30/06/2007

Aprovado em 26/02/2008

Versão final apresentada em 13/12/2007 